\title{
An Analysis of Sustainability Dimensions Ecology Cultivation Groupers in Saleh Bay of Sumbawa District, Indonesia
}

\author{
Muhammad Marzuki \\ (Aquaculture Departement, Mataram of University, Indonesia)
}

\begin{abstract}
This study aimed at determing value of the index and the sustainability status in terms of ecologic dimension and provide recommendations for policies on grouper aquaculture management in the Saleh Bay. Rap-Insus-Grouper (Rapid Appraisal of Sustainability-Index Grouper) modified from Rapfish program were use in this study. Results showed that the index level of sustainability in terms of ecology dimension were "31.23" for grouper respectively. This value laid between 25.00 and 49.9 indicating that both management status were "Less Sustainable". These values indicate that the ecologic conditions of that particular site were not supported sustainable management of the grouper aquaculture. Hence, government policing intervention through increased capital, technical training in aquaculture and processing as well as improvement in the market institution are required.
\end{abstract}

Keywords: Sustainability Analysis, Ecology, Grouper, Multi-Dimensional Scaling, Saleh Bay

\section{Introduction}

Saleh Bay water area has more than $70 \%$ of potential mariculture waters of Sumbawa. In the last five years, this water area accounted for more than $60 \%$ of marine aquaculture production Sumbawa. Saleh Bay waters potential for the development of marine aquaculture because it is supported by several factors: (1) has a long coastline; (2) has a lot of small islands; (3) The hydro-oceanographic conditions such as waves, currents and water transparency suitable for the growth of marine aquaculture commodities (Department of Marine and Fisheries of West Nusa Tenggara, 2009).

Socio-economic conditions of coastal communities are generally low Sumbawa, characterized by livelihood as subsistence fishermen fishing with a boat without a motor and simple fishing equipment. Life of fishermen increasingly exacerbated by the results obtained from the fishing activity is erratic depend on the season. In difficult economic conditions, because just relying upon income from fishing is erratic triggering them to conduct fishing practices are not environmentally friendly such as the use of explosives, potassium cyanide, coral mining, and others.

According to Marzuki et al., (2013) states that the ecological dimension is a key dimension for sustainable development guidelines require continuity of use of natural resources and environmental services for future generations. Ecological sustainability associated with maintaining the integrity of ecosystems, maintaining aquatic environmental capacity, and to improve the capacity and quality of aquatic ecosystems is a major concern. Ecological dimension was chosen to reflect how the utilization of water resources for marine aquaculture ecological impacts on the sustainability of resources and the environment and the ecosystem so that the activities can take place in a sustainable utilization.

Ecological attributes are chosen to reflect how utilization aquatic resources for marine aquaculture ecological impacts on the sustainability of resources and the environment and the aquatic ecosystem, so that aquaculture can be sustainable. Utilization of water for grouper aquaculture which exceedes the carrying capacity of water will affect the lack of continuity of these activities.

\subsection{Place and Time of Study}

\section{Method}

The research was conducted in coastal and marine areas Saleh Bay Sumbawa. Determining the location of the research done by purposive sampling based on the consideration that the four sub-districts are coastal and marine areas in Sumbawa Saleh Bay and there is activities cultivation of seaweed and grouper in floating cage system. Research carried out for one year from January to December 2011.

\subsection{Data Collection Method}

Mariculture sustainability analysis for commodity seaweeds and grouper floating net system was conducted Rap-Insus-Grouper (Rapid Appraisal -Index Sustainability for Grouper) have been modified from the program RAPFISH (Rapid Assessment Technique for Fisheries) (Kavanagh, 2001; Pitcher and Preikshot, 2001; Fauzi and Suzy, 2002). The stages of the management of marine aquaculture sustainability analysis for commodity seaweed and sea groupers floating cages system in the research area are as follows: 
(1) Identification and Determination Attributes

Determining the economic dimension attributes are attributes that affect the sustainability of marine aquaculture management for commodity grouper floating cages system. Attribute reflects how seaweed farming benefit micro and a macro economy that will sustain sustainability of marine aquaculture management for commodity seaweeds and grouper floating cages system.

(2) Preparation Score and Grading

The second phase of this analysis is to manufacture a score by scoring or ranking on attributes. Making the score refers to techniques RAPFISH (Pittcher and Preikshot, 2001; Susilo, 2003), the score is given a value "bad (bad)" which reflects the condition of the most profitable and otherwise the value of "good (good)", ie conditions the most profitable. Among the extreme value of "good" and "bad", there are usually one or more grades between. Referring to the approach used by Good et al., (1999) and Heersman et al., (1999), the rating given to each attribute are rated ranges between 0 - 3 Scoring depends on the circumstances of each attribute defined ranging from good to bad.

(3) The Process of Ordination

The position of the point of sustainability can be visualized in two dimensions (vertical and horizontal axis). Through the method of the rotation axis, the position of those points can be projected on a horizontal line where the extremes of "bad" were given a score of $0 \%$ and the extreme point of "good" was given a score of $100 \%$. MDS MDS (Multi-Dimensional Scaling) can present method ordinated effectively. Two points or the same object is mapped to a point adjacent to one another. Instead, objects are not the same or point represented by dots apart (Fauzi and Suzy, 2005). The next ordination process after the horizontal main reference point is (Susilo, 2003):

1. Make the other main reference point is "midpoint" is a good central points and midpoint bad. Two additional point will be the reference vertical direction ( "up" or "up" and "down" or "down") of ordination;

2. Make an additional reference point called the reference point "anchor" (anchors) are useful for the stabilizer and put points on the same position on the same multidimensional space;

3. Standardizing score for the individual attributes so that each attribute has a uniform weight and the difference between the measurement scale can be eliminated;

4. Title calculates the distance between the reference-point Euclidean distance squared method Alder et al., (2001) stated that the point ordinated by configuring the distance between points in t-dimension refers to the distance between points euclidiean. In the space of two-dimensional Euclidean distance is defined as follows:

$$
d={\sqrt{\left|x_{1}-x_{2}\right|^{2}+\left|y_{1}-y_{2}\right|^{2}}}^{2}
$$

While in n-dimensional distance Euclidien formulated as follows:

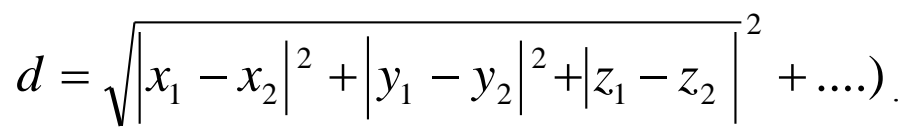

5. Make good ordinated for all dimensions and all attributes of algorithmic analysis of MDS. Data in the matrix are interval data showing the good and bad scoring. Score data is then normalized to minimize stress. One approach is to normalize the data is the value of $\mathrm{Z}$ (Alder et al., 2001).

$\mathbf{Z}$

$(\mathbf{x}-$

(4) The process of Rotation

To project these points on the horizontal line do a rotation, with the extremes of "bad" is given a score of $0 \%$ and the extreme point that "good" was given a score of $100 \%$. To ensure no risk of error in the position of a point that is the inverse mirror image goes through a "flip" for specific points with errors.

\subsection{Conformity Bodies for Marine Aquaculture}

\section{Result and Discussions}

The process of determining the location of marine aquaculture in waters suitable in the biophysical environment and the water quality is an important factor to ensure the continuity of marine aquaculture. Selection of proper farming location based suitability waters is very important because it affects the economic sustainability of farming. The availability of water for aquaculture space allocations should be applied in the 
context of an integrated planning approach to avoid conflicts of interest that will ultimately lead to environmental damage.

\subsection{Conformity Bodies for the Aquaculture grouper in Floating Cages System}

Conformity assessment waters as a determining factor in the development of grouper aquaculture in waters Saleh Bay Sumbawa Regency based on some parameters of conformity as follows: current speed, depth, brightness, $\mathrm{pH}$, salinity, substrate, DO and temperature of water. In this study, the determination of suitability class water for grouper aquaculture system is based on classification according to FAO (1976), but with consideration of the waters that were evaluated are the waters of the bay, so that the suitability classes are divided into three (3) classes of conformity that is very suitable (S1), accordingly (S2) and is not suitable (S3) with a score of respectively 3,2 and 1. Based waters suitability analysis results for grouper aquaculture marine area of the obtained water suitability by category are: a very appropriate marine area (S1) covering an area of 11511.48 ha or $24.63 \%$, corresponding water area (S2) covering an area of 16302.70 ha or $34.90 \%$ and the broad waters of the corresponding conditional (S3) covering an area of 16.31,41 ha or $96.47 \%$ and the broad waters are not appropriate $(\mathrm{S} 2+\mathrm{S} 2)$ covering an area of 2609.70 ha, or $5.58 \%$. In detail, the broad waters of suitability classes based on water for grouper aquaculture in Saleh Bay presented in Table 1.

Table 1. Potential According to Suitability Classes for Grouper Aquaculture In Floating Cages System

\begin{tabular}{|l|l|l|l|}
\hline \multirow{2}{*}{ No } & \multirow{2}{*}{ Class Suitability } & \multicolumn{2}{|c|}{ Potential } \\
\cline { 3 - 4 } & & $($ ha) & $(\%)$ \\
\hline 1 & Very Suitable (S1) & $11.511,48$ & 24,63 \\
\hline 2 & Suitable (S2) & $16.302,70$ & 34,88 \\
\hline 3 & In accordance Conditional (S3) & $16.313,41$ & 34,90 \\
\hline 4 & It is not in accordance with (N) & $2.609,70$ & 5,58 \\
\hline
\end{tabular}

The area of water for grouper culture in the floating cage, when broken down by district administration showed that most of these are in Sub Lape is an area of 10386 ha (37\%). The utilization rate is still very low water areas amounted to only $0.001 \%$, so that there is 10,376 ha of water area untapped. Furthermore, in the District Plampang dam waters are very suitable and appropriate for grouper aquaculture in cage covering an area of 6647 ha $(24 \%)$ and 8,150 ha $(29 \%)$. The utilization rate of water area is only $0,005 \%$ and $0,004 \%$, so there are still untapped waters covering an area of 6,616 ha and 8147 ha. Meanwhile, in the district of Moyo Hilir has the lowest water area and overall there has been no use of that area of 2,630 spacious suitability. Specifically, utilization and water potential for seaweed farming is detailed per-districts are presented in Table 2.

Table 2. Size of Conformity Utilization and Potential of Water for Grouper Aquaculture in Cage Specified

\begin{tabular}{|c|c|c|c|c|c|c|c|c|}
\hline \multicolumn{9}{|c|}{ District } \\
\hline \multirow[t]{2}{*}{ No } & \multirow[t]{2}{*}{ District } & \multirow[t]{2}{*}{ Class } & \multicolumn{2}{|l|}{ Potential } & \multicolumn{2}{|c|}{ Already Used } & \multicolumn{2}{|c|}{ Yet utilized } \\
\hline & & & (ha) & $\%$ & (ha) & $\%$ & (ha) & $\%$ \\
\hline \multirow[t]{3}{*}{1} & \multirow[t]{2}{*}{ Empang } & S1 & 900,88 & \multirow[t]{3}{*}{24} & \multirow[t]{3}{*}{32} & \multirow[t]{3}{*}{69} & \multirow[t]{3}{*}{6.616} & \multirow[t]{3}{*}{24} \\
\hline & & S2 & $5.746,32$ & & & & & \\
\hline & \multicolumn{2}{|l|}{ Amount } & $6.647,20$ & & & & & \\
\hline \multirow[t]{3}{*}{2} & \multirow[t]{2}{*}{ Moyo Hilir } & S1 & $1.404,69$ & \multirow[t]{3}{*}{10} & \multirow[t]{3}{*}{ - } & \multirow[t]{3}{*}{ - } & \multirow[t]{3}{*}{2.630} & \multirow[t]{3}{*}{9} \\
\hline & & S2 & $1.225,35$ & & & & & \\
\hline & \multicolumn{2}{|l|}{ Amount } & $2.630,04$ & & & & & \\
\hline \multirow[t]{3}{*}{3} & \multirow[t]{2}{*}{ Lape } & S1 & $7.231,08$ & \multirow[t]{3}{*}{37} & \multirow[t]{3}{*}{11} & \multirow[t]{3}{*}{24} & \multirow[t]{3}{*}{10.376} & \multirow[t]{3}{*}{37} \\
\hline & & S2 & $3.155,78$ & & & & & \\
\hline & \multicolumn{2}{|l|}{ Amount } & $10.386,87$ & & & & & \\
\hline \multirow[t]{4}{*}{4} & \multirow[t]{2}{*}{ Plampang } & S1 & $1.974,82$ & \multirow[t]{3}{*}{29} & \multirow[t]{3}{*}{3} & \multirow[t]{3}{*}{7} & \multirow[t]{3}{*}{8.147} & 29 \\
\hline & & S2 & $6.175,25$ & & & & & \\
\hline & Amount & & $8.150,07$ & & & & & \\
\hline & Suitability & & $27.814,18$ & 100 & 46 & 100 & 27.769 & 100 \\
\hline
\end{tabular}

Source: Results Analysis (2013)

Based on the analysis of the suitability of water for grouper culture in the floating cage, showed that in Saleh bay still has potential for very broad waters to be used for increased production of grouper. This condition line with government policy sets this region as a strategic area for the benefit of economic growth and as a center for the development of aquaculture to support the industrialization of aquaculture, especially marine aquaculture. Grouper in the floating cage in the area of research over the last five years has not developed, this 
business requires capital large enough so it is generally done by entrepreneurs owners of big capital. The current local government policies, lack of prioritizing the development of grouper culture compared to the cultivation of seaweed that is implemented through PIJAR program.

Lack of government attention to the development of commodity grouper farming led to the development of this commodity tend not growing compared with seaweed. But in the future due to the increasing market demand and interest of investors investation on grouper aquaculture and is supported by the availability of waters are very widespread in the study area, the cultivation should pay attention to the carrying capacity of the water environment to ensure fish farming is economically sustainable.

\subsection{Sustainability Status Multidimensional}

The results of the analysis of Rap-Grouper Insus Saleh Bay Sumbawa against 10 attributes affect the ecological dimension, obtained that the value of the index at the level of sustainability of ecological dimensions of 54.87. The value lies between 51.00 to 75.00 means "Sustainable Enough". The value of sustainability index over 50 indicates the ecology of water was sufficient to support the management of grouper aquaculture in cage, but the value of the index is very close to less sustainable, so that when the ecology of waters are not managed or left as it is today, it will affect the sustainability of other dimensions, so that the management of grouper aquaculture in cage in Saleh bay Sumbawa increasingly unsustainable. In detail, the analysis of the ecological dimensions of sustainability status index grouper aquaculture management with Saleh bay in floating cages system in Saleh bay is presented in Figure 1.

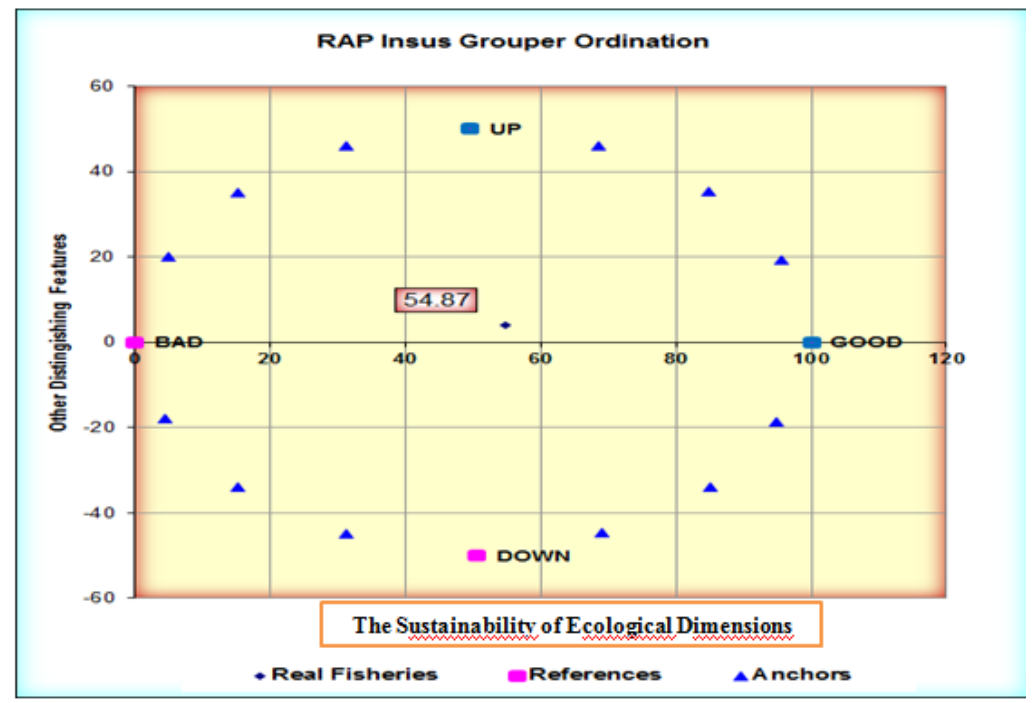

Figure 1. The index value and ecological dimensions of sustainability status of grouper aquaculture management in floating cages system in Saleh Bay Sumbawa

Based on the analysis of the 10 attributes leverage ecological dimension obtained three (3) attributes that are sensitive to the level of sustainability of ecological dimension, namely: (1) Threats to Water Quality (RMS-2.70); (2) Sedimentation Rate (RMS-1.44); and (3) Fertility Status Bodies (RMS-1.29). Changes to the 3rd leverage this factor will easily affect the increase or decrease in the value of the ecological dimensions of sustainability Indes. In detail, the sensitivity attributes ecological dimension of sustainability management in cage grouper aquaculture in the Saleh bay presented in Figure 2. 


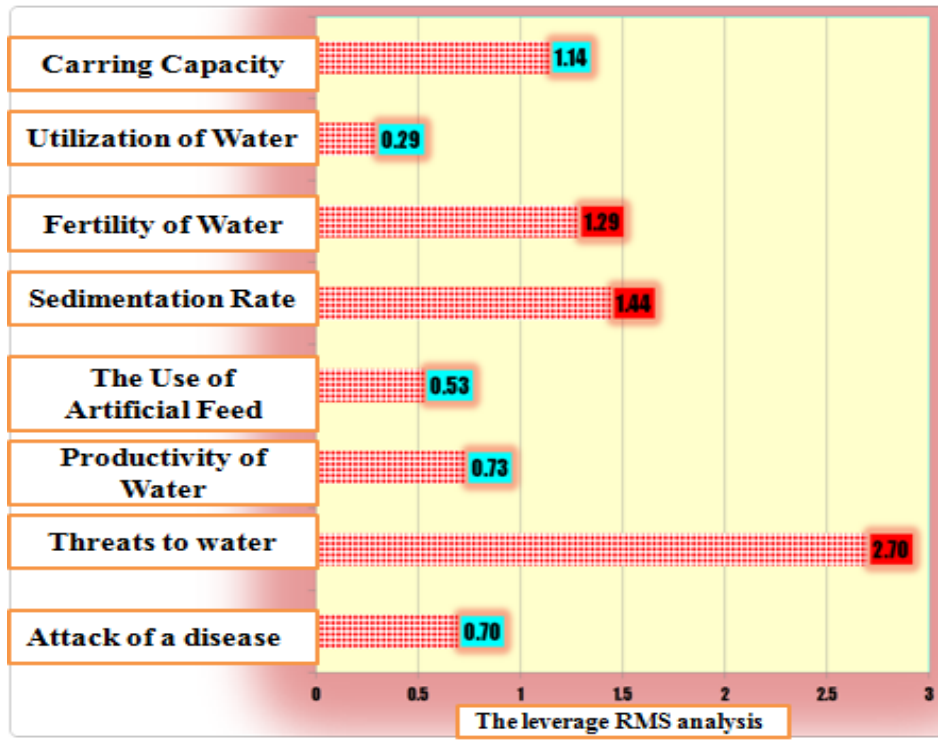

Figure 2. The sensitivity of ecological dimension attributes expressed in the change root mean square (RMS)

\section{(1) Threats to Water Quality} scale sustainability $0-100$

Attributes "Threats to Water Quality" is a sensitive attribute on the sustainability of grouper aquaculture in the floating cage system on the ecological dimension because they a threat to the water quality will affect the carrying capacity of the waters thus disturbing the ecological system in the waters. Threats to water quality in the study area comes from destructive fishing activities and development activities in up-land such as domestic waste, aquaculture, hatchery, port activity, agriculture, and mining. Waste activity by Iswiasri and Martono (2007) traditional or illegal gold mining (Gold Miners Without Permission) often results in water pollution, so that the environmental monitoring to be conducted to prevent damage to the marine environment.

\section{(2) Sedimentation Rate}

Attributes "Sedimentation Rate" is a sensitive attribute on the sustainability of grouper aquaculture in floating cage system on the ecological dimension, because the rate of sedimentation rates will affect pollution and water quality for grouper aquaculture in cage. Based on data from the Department of Fisheries NTB (2009) showed that the rate of sedimentation waters the research region at $28 \mathrm{mg} / \mathrm{cm} 2 /$ day category "Medium to Heavy". Although the current state of the sedimentation rate is still the category of moderate to severe, but activity in the mainland, if not managed properly potentially increasing sedimentation. Sediment into the waters of the sea in the Saleh bay can come from erosion of land that goes into rivers and coastal erosion.

\section{(3) Fertility of Water}

Attributes "Fertility of Water" is a sensitive attribute on the sustainability of grouper aquaculture in floating cage system on the ecological dimension, the fertility waters because they affect the quality of the waters for the growth and development of cultivated grouper. Status refers to the fertility waters. Based on the content of nitrate and phosphate as well as the abundance of phytoplankton in the area of research, the fertility status of the waters of the category "Mesotrophic". Walapaun the current state of the current fertility status mesotrophic waters, but the rise of activity in the mainland, if not properly managed could potentially increase fertility status to a level hypertrophic waters.

\section{Conclusions}

Based on the analysis of leverage against 10 (ten) attribute ecological dimension, for grouper aquaculture floating net cage systems obtained 3 (three) sensitive attributes, namely: serious threat to water quality, sedimentation rate and the fertility status of waters.

\section{Acknowledgement}

Infinite thanks to Mr. Ridwan for a great team work and who have helped.

\section{References}

[1]. Alder, E., M.A. Hoon, K.L. Mueller, J. Chandrashekar, J.P. Ryba dan C.S. Zuker, 2000. A novel family of mammalian taste receptors. Cell, 100, 693-702 
[2]. Anggadiredja, J.T., A. Zantika, H. Purwoto dan S. Istini, 2006. Seaweed, Cultivation, Processing and Marketing of Fishery Commodities Potential. Penebar Swadaya. Jakarta, 147 hal.

[3]. Marine and Fisheries Departement of West Nusa Tenggara, 2009. Detailed Spatial Plan Saleh Bay Region. Marine and Fisheries Agency of West Nusa Tenggara. Mataram.

[4]. Fauzi A dan Anna Z. 2005. Modeling of Marine and Fisheries Resource for Policy Analysis. Jakarta, Gramedia.

[5]. Fauzi. A dan S. Anna. 2002. Status Evaluation of Fisheries Development Sustainability, RAPFISH Application, Case Study of DKI Jakarta Coastal Waters. Journal of Coastal and Marine. Vol. 4(3).

[6]. Good, N., J.B. Schafer, J.A. Konstan, A. Borchers, B. Sarwar, J. Herlocker dan J. Riedl, 1999. Combining collaborative filtering with personal agents for better recommendations. Proceedings of AAAI, 99, 439-446.

[7]. Heershman, M.J., J.W. Good, T. Bernd, Cohen, R.F. Goodwin, V. Lee dan P. Pogue, 1999. The Effectiveness of Coastal Zone Management in theUnited States. Journal Coastal Management, 27: 113-138.

[8]. Inswiasri dan Martono Hendro, 2007. Pollution in the region of the People Gold Mine. Media Health Research, 18 (3): $42-57$

[9]. Kavanagh P. 2001. Rapid Appraisal of Fisheries (RAPFISH) Project. University of British Columbia, Fisheries Centre.

[10]. Marzuki, M. Nurjaya, W.I, Purbayanto, A. 2014. Sustainability Economic Dimension Review of Marine Aquaculture Management in Saleh Bay Sumbawa. J. Sosek KP, 8 (2), 2013, 157-166.

[11]. Pitcher, T.J. and Preikshot, D.B. 2001. Rapfish: A Rapid Appraisal Technique to Evaluate the Sustainability Status of Fisheries. Fisheries Research 49(3): 255-270

[12]. Santoso, L. dan Y.T. Nograha, 2008. Ice-ice Disease Control to review increase seaweed production in Indonesia. Journal of Fisheries Saintek, 3 (2): 2008.

[13]. Susilo, S.B, 2003. Sustainability Development of Small Island: A Case Study Island Village Bake and Pari Island, Islands-Seribu, Jakarta. Dissertation. Bogor Agricultural Institute Master Program.

[14]. Walpole, 1995. Introduction to Statistics. Gramedia Pustaka Utama. Jakarta.

[15]. Yulianto, K, 2004. The Phenomenon Causes a Loss in the Controlling Factor Karaginofit Cultivation in Indonesia. Oceana, 29 (2): $17-23$. 